\title{
Bakri postpartum balloon: an obstetrician's armamentarium in managing post-partum haemorrhage
}

\section{Arti Sharma*, Neeta Bansal, Monika Ramola, Priyanka Chaudhari, Suman Pant, Neha Panwar}

Department of Obstetrics and Gynecology, SGRRIM and HS, Dehradun, Uttarakhand, India

Received: 05 March 2020

Accepted: 01 April 2020

\section{*Correspondence:}

Dr. Arti Sharma,

E-mail: artishubh@yahoo.com

Copyright: ( $)$ the author(s), publisher and licensee Medip Academy. This is an open-access article distributed under the terms of the Creative Commons Attribution Non-Commercial License, which permits unrestricted non-commercial use, distribution, and reproduction in any medium, provided the original work is properly cited.

\section{ABSTRACT}

Background: Post-partum haemorrhage (PPH), an obstetric emergency that can complicate vaginal or cesarean deliveries and associated with serious complications. Guidelines for the management of PPH involve a stepwise escalation of pharmacological and eventual surgical approaches. In women who do not respond to uterotonics or medical treatment, a variety of procedures, such as arterial embolization, surgical ligation of the uterine arteries or obstetric hysterectomy, may be used. The Bakri balloon is an intrauterine device indicated to reduce or control PPH temporarily when conservative treatment is warranted. Here, we are presenting case series of primary atonic PPH and which were managed by Bakri Balloon Tamponade (BBT).

Methods: This case series included five women with PPH managed by Bakri balloon as a conservative therapeutic option.

Results: All five women were in age group between 23 years to 34 years. The causes of PPH were uterine atony, retained placenta and central placenta previa. The Bakri balloon was successful in controlling hemorrhage in all women (five of five) who did not respond to medical uterotonic treatment.

Conclusions: Bakri balloon is a simple, easy to use and effective method for conservative management of acute PPH. This device reduces bleeding, shortens the hospital stay and avoids the need for more aggressive procedures.

Keywords: Bakri balloon, Cesarean section, Post-partum haemorrhage, Uterine atony, Uterine tamponade, Vaginal delivery

\section{INTRODUCTION}

Post-partum haemorrhage (PPH) is a major cause of maternal morbidity and causes a large proportion of maternal deaths worldwide. ${ }^{1}$ It mainly occurs without warning signs or symptoms and often in absence of predisposing factors, contributing to hysterectomies in at least $50 \%$ of cases. ${ }^{2}$ Primary $\mathrm{PPH}$ is defined as an estimated blood loss during the first 24 hours postpartum, of more than $500 \mathrm{ml}$ in vaginal delivery and $1000 \mathrm{ml}$ in caesarean delivery, being uterine atony, the most common cause of blood loss. ${ }^{3}$ In situations of intractable $\mathrm{PPH}$, and where a hysterectomy is otherwise not indicated, balloon tamponade came as a new weapon in obstetrician's armamentarium before considering surgical procedures like laparotomy or peripartum hysterectomy, which is often delayed or may be unavailable thereby costing the women her life. Here, we discuss a series of 5 cases of PPH with varied clinical presentation managed by BBT. We used the Bakri postpartum balloon (Cook Medical, Spencer, IN).

\section{METHODS}

This case series included women $(n=5)$ who delivered in the department of obstetrics and gynecology, SGRRIM 
and HS, Dehradun and had PPH or referred from outside as a case of PPH. After detailed history and examination, the protocol for management of PPH was followed.

In cases of PPH following vaginal delivery urinary bladder drainage was ensured by inserting Foleys catheter. Exploration of vagina and cervix was done to localize the site of hemorrhage. Lacerations were surgically managed. Retained placental tissue was removed if present and uterotonics were given for uterine atony. If hemorrhage continued even after the use of uterotonics, the Bakri balloon was inserted and inflated with sterile saline up to the desired volume. The drainage port of the balloon was connected to a fluid collection bag to monitor blood loss. The balloon was kept inflated for maximum up to 24 hours with careful monitoring of the hemorrhage. The balloon was deflated gradually or removed completely when adequate hemostasis was achieved.

When the balloon was placed at the time of cesarean section, an assistant pulled the distal end of the balloon shaft through the cervix into the opened uterus. After the balloon was inflated with approximately $100 \mathrm{ml}$ of sterile saline the hysterotomy incision was closed carefully in order to avoid damaging the balloon. Later on, after closure further inflation of balloon with sterile saline was done up to desired volume.

The obstetrical indications for BBT, the amount of total blood loss, the total time of the balloon was left in situ, the volume of the sterile saline used for inflation of balloon was recorded.

\section{Case series}

\section{Case 1}

A 24 years old unbooked, P1L1, presented in emergency in shock with excessive bleeding per vaginum and passage of clots. She had history of vaginal delivery at home 5 hours ago. On examination her pulse was 120 bpm, blood pressure (BP) $70 \mathrm{~mm}$ systolic and severe pallor was present. On abdominal examination flabby, non-tender, uterus was felt to be of 20 -week size. Per vaginal examination revealed presence of retained placenta with excessive bleeding per vaginum. Her hemoglobin was $4.5 \mathrm{gm} \%$ and coagulation profile were normal.

Manual removal of placenta done and PRBC transfusion given. Even then patient had atonic PPH which was managed with uterine massage and uterotonics. However, bleeding continued and decision for intrauterine balloon tamponade was taken. Vaginal insertion of Bakri Balloon was done and it was inflated with $350 \mathrm{ml}$ of sterile saline. Uterus became contracted and bleeding was controlled. Bakri balloon was removed after 24 hours. Patient condition improved thereafter and was discharged on postnatal day 5 .

\section{Case 2}

A 23 years old unbooked, G2P1L1, presented with term pregnancy in active labour with severe anemia and thrombocytopenia. On examination her pulse was 90 beats per minute, BP- 100/70 $\mathrm{mmHg}$ and severe pallor was present. On abdominal examination, uterus term size, contractions present with normal fetal heart sounds. Laboratory investigations were suggestive of $\mathrm{Hb}-5 \mathrm{gm} / \mathrm{dl}$ and platelets-60,000 per cubic mm. Patient underwent vaginal delivery and had atonic PPH which was managed with uterine massage and uterotonics initially. But still bleeding continued. Intrauterine balloon tamponade was done with Bakri balloon. Two packed red cell transfusion given. Uterus was well contracted, bleeding controlled. Bakri balloon removed after 18 hours. Her condition improved thereafter and was discharged in satisfactory condition.

\section{Case 3}

A 23 years old G2P1L0, presented to hospital at 32 weeks 3 days with abruption placentae with severe anaemia in active labour with bleeding per vaginum. On examination pulse rate was 86 beats per minute, BP$100 / 70 \mathrm{mmHg}$ with clinically evident severe pallor was present. On abdominal examination, uterus was 34 weeks size, tense and tender. Her hemoglobin was $6 \mathrm{gm} \%$ and liver, renal and coagulation function tests were normal. Patient had atonic PPH after preterm vaginal delivery which was managed with uterine massage and uterotonics. However, bleeding continued. Intrauterine balloon tamponade was done with Bakri balloon. Patient's vitals became stable, bleeding controlled and Bakri balloon was removed after 24 hours. Three packed red blood cell transfused meanwhile and patient was discharged in stable condition.

\section{Case 4}

A 26 years old primigravida presented with 38 weeks pregnancy with bleeding per vaginum. She was a referred case with USG report of central placenta previa. On caesarean section there was continuous oozing from lower segment of uterus at the site of placental attachment. Insertion of BBT was done by abdominal route. An assistant helped by pulling the distal end of the balloon shaft through the cervix into the opened uterus. Then the balloon was inflated with $100 \mathrm{~mL}$ of sterile saline solution. The hysterotomy incision was closed carefully in order to avoid damaging the balloon. After closure of uterine incision balloon was inflated with extra $250 \mathrm{ml}$ of sterile saline. Patients vitals improved and bleeding controlled. Balloon was removed after 15 hours. Patient showed good recovery thereafter.

\section{Case 5}

A 34 years old P4L4 came with history of preterm delivery at home at 30 weeks gestation with foul smelling 
vaginal discharge, retained products of conception and excessive bleeding per vaginum. On examination severe pallor was present and uterus was atonic. Suction evacuation was done following which patient continued to bleed despite uterotonics. Bakri balloon was inserted and inflated with $150 \mathrm{ml}$ of sterile saline. Bleeding was controlled and Bakri balloon removed next day. Patient discharged in satisfactory condition.

\section{RESULTS}

In this case series five women had BBT intervention. Two women came as postnatal case with PPH while three women delivered in study hospital and had PPH. Out of five women four had vaginal delivery and one had emergency caesarean section.

All five women were in age group between 23 years to 34 years. The other risk factors and co morbid conditions contributed to occurrence of PPH were history of home delivery, severe anemia, thrombocytopenia, abruption placentae and puerperal sepsis. Specially in case 5 home delivery and incomplete expulsion of placenta gave rise to sepsis and PPH. Total blood loss was $1500 \mathrm{ml}$ in case 2 and case 3, whereas it was $2000 \mathrm{ml}$ in case 1 and case 5.Maximum blood loss of $2500 \mathrm{ml}$ was present in case 4 with type four central placenta previa (Table 1).

Table 1: Characteristics of women with Bakri balloon.

\begin{tabular}{|lllll|}
\hline Case & Age & Parity & Risk factors and other comorbidity & Total blood loss (ml) \\
\hline 1 & 24 years & P1L1 & History of home delivery, severe anemia & 2000 \\
\hline 2 & 23 years & G2P1L1 & Severe anemia, thrombocytopenia & 1500 \\
\hline 3 & 23 years & G2P1L0 & Abruptio plcentae, severe anemia & 1500 \\
\hline 4 & 26 years & G1P0L0 & Central placenta previa & 2500 \\
\hline 5 & 34 years & P4L4 & History of home delivery, retained placenta, puerperal sepsis & 2000 \\
\hline
\end{tabular}

Table 2: Cause of PPH managed by Bakri balloon.

\begin{tabular}{|ll|}
\hline Case & Cause \\
\hline 1 & Total placental retention \\
\hline 2 & Uterine atony \\
\hline 3 & Uterine atony \\
\hline 4 & Central placental previa \\
\hline 5 & Partial placental retention \\
\hline
\end{tabular}

The causes of PPH were uterine atony, retained placenta and central placenta previa with continuous bleeding from flabby lower uterine segment. In case 1 complete placenta was retained which was delivered by manual removal while in case 5 fragments of placenta were retained so suction evacuation was done (Table 2). The indication of Bakri balloon insertion was occurrence of continuous PPH even after uterine massage, use of uterotonics and other measures like manual removal of placenta, suction evacuation. Though maximum capacity of balloon was $500 \mathrm{ml}$ but PPH controlled by lesser volume of saline used for inflation. The volume of sterile saline solution used for inflation of Bakri balloon was minimum $150 \mathrm{ml}$ to maximum $400 \mathrm{ml}$. Total time period up to which Bakri balloon was left in situ was 24 hours, 18 hours, 24 hours, 15 hours and 20 hours in case 1 to 5 respectively. When adequate haemostasis was achieved the balloon was deflated gradually and then removed completely (Table 3 ).

In all five cases hemorrhage was controlled and need for more aggressive surgical procedures such as systematic devascularization, bilateral uterine artery embolization or peripartum hysterectomy was avoided.

Table 3: Characteristics related to Bakri balloon.

\begin{tabular}{|llll|}
\hline Case & Indications of BBT & $\begin{array}{l}\text { Volume of sterile saline } \\
\text { used for inflation (m) }\end{array}$ & $\begin{array}{l}\text { Total time of balloon } \\
\text { left in situ (hours) }\end{array}$ \\
\hline 1 & $\begin{array}{l}\text { Retained placenta (continuous hemorrhage despite } \\
\text { manual removal) }\end{array}$ & 350 & 24 \\
\hline 2 & Atonic PPH & 250 & 18 \\
\hline 3 & Atonic PPH & 400 & 24 \\
\hline 4 & $\begin{array}{l}\text { Central placental previa with bleeding from lower } \\
\text { segment }\end{array}$ & 350 & 15 \\
\hline 5 & $\begin{array}{l}\text { Retained fragments of placental tissue (continuous } \\
\text { hemorrhage despite suction evacuation) }\end{array}$ & 150 & 20 \\
\hline
\end{tabular}




\section{DISCUSSION}

Uncontrolled PPH is the most common cause of maternal death and disability worldwide. ${ }^{2}$ Uterine atony following a spontaneous vaginal delivery is the most frequent reason for $\mathrm{PPH} .{ }^{3}$ The concept of uterine packing has long been utilized for controlling severe uterine haemorrhage, but Bakri et al, first proposed using a specifically designed intrauterine balloon catheter, which he did in a series of five women with haemorrhage from low-lying placenta or cervical pregnancies. ${ }^{4}$ Subsequently, various types of balloon catheters, including the Foley catheter, Sengstaken-Blakemore tube, Rusch balloon, and condom catheters have been adapted for similar clinical scenarios. ${ }^{5-7}$ Bakri balloon is a balloon tamponade indicated for women not responding to uterotonics and uterine massage.

It is used to control haemorrhage due to uterine atony in the upper segment of the uterus and to control bleeding in the lower uterine segment secondary to placental implantation in the lower uterine segment. It ensures temporary control or reduction of PPH when conservative management of uterine bleeding is warranted. the features and benefits of this balloon are that it is latex free, shape conforms to uterine cavity, easy to place and remove and it has a drainage lumen for monitoring of ongoing blood loss. Some contraindications to its use are purulent infections of the vagina, cervix or uterus, untreated uterine anomaly, disseminated intravascular coagulation and arterial bleeding requiring surgical exploration which have also been adopted in various authoritative guidelines. According to the literature, intrauterine balloon tamponade can be deployed concurrently with other conservative techniques. Notably, the successful application of the 'uterine sandwich' using uterine compression sutures in conjunction with the Bakri balloon tamponade has been described in two patients with massive haemorrhage and in a series of five women with PPH due to uterine atony. ${ }^{8-10} \mathrm{~A}$ series of 11 cases with placenta previa or uterine atony using Hayman sutures combined with the Bakri balloon have also been described, with no major complications and a $100 \%$ success rate. ${ }^{11}$

Another series of 20 cases was published recently, in which the Bakri balloon was used as the treatment of first choice in 20 cases. Out of these, 12 were successfully managed with the balloon alone but six warranted the balloon and B-Lynch sutures, while two finally had a hysterectomy. ${ }^{12}$ The successful outcome of balloon tamponade is reported to be $80-100 \% .^{13}$ Some major complications have also been reported following the use of balloon catheters. Caesarean scar dehiscence has been associated with intrauterine balloon tamponade placement after a second-trimester dilatation and evacuation. ${ }^{14}$ Ten weeks following application of uterine compression sutures combined with Rusch intrauterine balloon tamponade, uterine necrosis ensued. ${ }^{15}$ The authors therefore suggested looking out for uterine blanching when applying such balloon/sandwich techniques. Intraluminal pressure was objectively measured while using the Bakri balloon and showed that it did not exceed the patient's systolic pressure when tamponade becomes established. ${ }^{16}$ Thus, when used alone, the intrauterine balloon is unlikely to give rise to uterine necrosis, but if used in combination with compression sutures, the risk could well increase.

The mechanism of action of BBT is not yet well understood. It has been speculated that the balloon creates an intrauterine pressure greater than the systemic arterial pressure. ${ }^{17}$ Georgiou recently examined the mechanism of the proposed tamponade effect. ${ }^{16}$ The intraluminal pressure within a Bakri balloon was determined during the establishment of a positive 'tamponade test'. ${ }^{17}$ This study included two cases and both of them had the systolic blood pressure higher than the intraluminal pressure of the Bakri balloon when a positive 'tamponade test' was established. ${ }^{16}$ Yorifuji measured the stiffness of the uterine corpus and cervix by radiation force impulse elastography before and after BBT. ${ }^{18}$ Uterine stiffness increased immediately after insertion of the balloon, suggesting that the balloon induced uterine contractions.

BBT is a non-invasive, conservative method of PPH management. Laparotomy and hysterectomy may be avoided in many cases. The use of BBT is easy to learn and the balloon can be inserted quickly. BBT does not exclude the use of other procedures if necessary. Even in cases with failure it may provide a temporary tamponade effect and time to prepare for other interventions or patient transfer. In this series BBT placement-controlled bleeding in case of placenta previa. However, in a case study of 137 patients the overall success rate was $75 \%$ for placenta previa patients. Possible factors related to failure of BBT for placenta previa patients were prior cesarean section history, anterior placentation, thrombocytopenia and presence of DIC at the time of catheter insertion. ${ }^{19}$

Bakri balloon tamponade is a readily available, effective and safe procedure for the treatment of postpartum hemorrhage and can be used in cases not responding to standard management. However, BBT cannot be used in life-threatening situations with massive bleeding that is not responding to any conservative management, and emergency postpartum hysterectomy in these cases may be needed.

\section{CONCLUSION}

Postpartum haemorrhage is a potentially life-threatening event. Given that the technology is simple to deploy and with minimal adverse effects, a balloon tamponade method should become a familiar component of existing guidelines for the management of PPH, although not as an isolated form of therapy. Balloon tamponade was the least invasive and most rapidly implemented, and that it seemed logical to use it in suitable cases 
Funding: No funding sources

Conflict of interest: None declared

Ethical approval: The study was approved by the Institutional Ethics Committee

\section{REFERENCES}

1. World Health Organization. Attending to 136 Million Births, Every Year: Make Every Mother and Child Count: The World Health Report 2005. Geneva: WHO; 2005:62-3.

2. Hazra S, Chilaka VN, Rajendran S, Konje JC. Massive postpartum haemorrhage as a cause of maternal morbidity in a tertiary hospital. J Obstet Gynaecol. 2004;24:519-20.

3. Abdel-Aleem H, El-Nashar I, Abdel-Aleem A: Management of severe postpartum hemorrhage with misoprostol. Int J Gynaecol Obstet. 2001;72:75.

4. Bakri YN, Amri A, Abdul Jabbar F. Tamponadeballoon for obstetrical bleeding. Int $\mathrm{J}$ Obstet Gynecol. 2001;74:139-42.

5. Albayrak M, Ozdemir I, Koc O, Demiraran Y. Postpartum haemorrhage from the lower uterine segment secondary to placenta praevia/accrete: successful conservative management with Foley tamponade. Aust N Z J Obstet Gynaecol. 2011;51:377-80.

6. Seror J, Allouche C, Elhaik S. Use of SengstakenBlakemore tube in massive postpartum hemorrhage: a series of 17 cases. Acta Obstet Gynecol Scand. 2005;84:660-4.

7. Georgiou C. Balloon tamponade in the management of postpartum haemorrhage: a review. BJOG. 2009;116:748-57.

8. Danso D, Reginald P. Combined B-Lynch suture with intrauterine balloon catheter triumphs over massivepostpartum haemorrhage. BJOG. 2002;109:963.

9. Price N, Whitlaw N, B-Lynch C. Application of the B-Lynch brace suture with associated intrauterine balloon catheter for massive hemorrhage due to placenta accreta following a second trimester miscarriage. J Obstet Gynaecol. 2006;3:267-8.

10. Nelson WL, O'Brien JM. The uterine sandwich for persistent uterine atony: combining the B-Lynch compression suture and an intrauterine Bakri balloon. Am J Obstet Gynecol. 2007;196:e9-10.

11. Yoong W, Ridout A, Memtsa M. Application of uterine compression suture in association with intrauterine balloon tamponade (uterine sandwich) for postpartum haemorrhage. Acta Obstet Gynecol Scand. 2012;91:147-51.

12. Diemert A, Ortmyer G, Hollwitz B. The combination of intrauterine balloon tamponade and the B-Lynch procedure for the treatment of severe postpartum haemorrhage. Am J Obstet Gynecol. 2012;206:65.e14.

13. Georgiou C. A review of current practice in using balloon tamponade technology in the management of postpartum haemorrhage. Hypertens Res Preg. 2014;2:1-10.

14. Soon R, Aeby T, Kaneshiro B. Cesarean scar dehiscence associated with intrauterine balloon tamponade placement after a second trimester dilatation and evacuation. Hawaii Med J. 2011;70:137-8.

15. Lodhi W, Golara M, Karangaokar V, Yoong W. Uterine necrosis following application of combined uterine compression suture with intrauterine balloon tamponade. J Obstet Gynaecol. 2012;32:30-1.

16. Georgiou C. Intraluminal pressure readings during the establishment of a positive "tamponade test" in the management of postpartum haemorrhage. BJOG. 2010;117:295-303.

17. Condous GS, Arkulkumaran S, Symonds I, Chapman R, Sinha A, Razvi K. The 'tamponade test' in the management of massive postpartum hemorrhage. Obstet Gynecol. 2003;101:767-2.

18. Yorifuji T, Tanaka T, Makino S, Koshiishi T, Sugimura M, Takeda S. Balloon tamponade in atonic bleeding induces uterine contraction: attempt to quantify uterine stiffness using acoustic radiation force impulse elastography before and after balloon tamponade. Acta Obstet Gynecol Scand. 2011;90:1171-2.

19. Cho HY, Park YW, Kim YH, Jung I, Kwon JY. Efficacy of intrauterine Bakri balloon tamponade in cesarean section for placenta previa patients. PLoS One. 2015;10(8):e0134282.

Cite this article as: Sharma A, Bansal N, Ramola M, Chaudhari P, Pant S, Panwar N. Bakri postpartum balloon: an obstetrician's armamentarium in managing post-partum haemorrhage. Int J Reprod Contracept Obstet Gynecol 2020;9:2113-7. 